\title{
An evolutionary frame of work to study physiological adaptation to high altitudes
}

\author{
Un marco conceptual para estudiar adaptaciones fisiológicas a altas altitudes
}

\author{
ENRICO L. REZENDE ${ }^{1 *}$, FERNANDO R. GOMES ${ }^{1}$, CAMERON K. GHALAMBOR ${ }^{2}$, \\ GREGORY A. RUSSELL ${ }^{1,3}$ \& MARK A. CHAPPELL ${ }^{1}$
}

\author{
${ }^{1}$ Department of Biology, University of California, Riverside, California 92521, USA \\ ${ }^{2}$ Department of Biology, Colorado State University, Fort Collins, Colorado 80523, USA \\ ${ }^{3}$ University of California White Mountain Research Station, Bishop, California 93514, USA \\ *E-mail for corresponding author: enrico.rezende@email.ucr.edu
}

\begin{abstract}
How complex physiological systems evolve is one of the major questions in evolutionary physiology. For example, how traits interact at the physiological and genetic level, what are the roles of development and plasticity in Darwinian evolution, and eventually how physiological traits will evolve, remains poorly understood. In this article we summarize the current frame of work evolutionary physiologists are employing to study the evolution of physiological adaptations, as well as the role of developmental and reversible phenotypic plasticity in this context. We also highlight representative examples of how the integration of evolutionary and developmental physiology, concomitantly with the mechanistic understanding of physiological systems, can provide a deeper insight on how endothermic vertebrates could cope with reduced ambient temperatures and oxygen availability characteristic of high altitude environments. In this context, high altitude offers a unique system to study the evolution of physiological traits, and we believe much can be gained by integrating theoretical and empirical knowledge from evolutionary biology, such as life-history theory or the comparative method, with the mechanistic understanding of physiological processes.
\end{abstract}

Key words: adaptation, evolutionary processes, natural selection, life-history, oxygen availability, phenotypic plasticity.

\section{RESUMEN}

Una de las preguntas más importantes en fisiología evolutiva es cómo evolucionan los sistemas fisiológicos complejos. Por ejemplo, actualmente sabemos poco sobre la interacción entre varios rasgos a niveles genéticos y fisiológicos, sobre el papel de la plasticidad fenotípica durante distintas etapas del desarrollo y madurez para la evolución fisiológica dentro de un linaje. En este trabajo explicamos el marco conceptual ocupado por fisiólogos evolutivos en la actualidad para estudiar adaptaciones fisiológicas a nivel evolutivo y el papel de la plasticidad dentro de la evolución Darwiniana. Citamos ejemplos de cómo la integración de la fisiología evolutiva y del desarrollo nos permitió un mayor entendimiento de cómo vertebrados endotérmicos pueden "adaptarse" a altas altitudes. Los organismos de alta altitud ofrecen un excelente sistema para estudiar la evolución de rasgos fisiológicos, y hay mucho por aprender en ese contexto al integrarse el conocimiento teórico y empírico de la biología evolutiva, tales como la teoría de historia de vida y el método comparativo, con el conocimiento mecanístico de los procesos fisiológicos.

Palabras clave: adaptación, procesos evolutivos, selección natural, historia de vida, disponibilidad de oxígeno, plasticidad fenotípica.

\section{INTRODUCTION}

Studying metabolic adaptations to high altitude (e.g., Rosenmann \& Morrison 1975) provides a very interesting and useful model to understand the evolution of complex physiological systems, for many reasons. First, the selective pressures involved are known: hypoxia and cold (lower hypobaria or higher atmospheric radiation seem to be less relevant for birds or mammals; Monge \& León-Velarde 1991). Second, considerable research on the physiological basis of aerobic performance has been done and the transport of $\mathrm{O}_{2}$ from lungs to 
tissues have been carefully described (Richardson et al. 1999, Bassett \& Howley 2000). Third, we now have a better understanding of the genetic basis of aerobic metabolism and its physiological correlates through the use of quantitative genetics and selection experiments (e.g., Dohm et al. 2001, Nespolo et al. 2003). Finally, the tight association between aerobic capacity and sustained locomotor and/or thermoregulatory performance in endotherms makes the former a likely target of selection, which has been recently shown to be the case in wild deer mice in natural habitats (Hayes \& O'Connor 1999).

Despite considerable research on the topic, many questions about how organisms adapt to high altitudes remain. For example, the relative contributions of genetic, maternal, developmental and environmental factors determining the adult phenotype (and how these factors interact) are not fully understood (e.g., Brutsaert 2001, Rupert \& Hochachka 2001). How animals respond differently to variable altitudes given their inherent nature and evolutionary history (e.g. mammals do not have feathers), and which responses are adaptive in the true Darwinian sense may depend on several factors (e.g., Garland \& Adolph 1991, Garland \& Carter 1994, Feder et al. 2000). In light of the current knowledge of evolutionary biology, physiologists acknowledge that not all traits are adaptive, and past history, genetic structure of the population, among many other factors, can influence for physiological patterns observed in different conditions. Here we attempt to (1) summarize the current framework on how to study physiological adaptation, given the background physiologists now have from evolutionary biology; (2) demonstrate how this framework can be applied in the study of altitude adaptation and; (3) provide incentive to those students interested in physiology to learn "not only on how animals work, but also how physiological systems evolve'.

\section{Cardiac output and the concept of adaptation}

Endotherms inhabiting high altitudes face a double challenge: they must thermoregulate and power activity in an environment where both temperature and oxygen partial pressures are low. In this context, physiologists have implicitly assumed that maximizing $\mathrm{O}_{2}$ delivery to the tissues in hypoxic environments is adaptive. However, even if this is the case, 'adaptation' and its various definitions must be differentiated because of their underlying causes and levels in which they occur (see also Monge \& León-Velarde 1991). Consider the following hypothetical example: a population of mammals inhabiting lowlands colonizes higher altitudes. Initially, as animals move higher, heart rate and stroke volume increase to provide more $\mathrm{O}_{2}$ to the tissues, and these changes are perceived as adaptive because without them, animals would have asphyxiated as $\mathrm{O}_{2}$ availability decreased. Phenotypic plasticity would account for this pattern (e.g., physiological changes occurred within each individual's lifetime), and therefore higher cardiac output would be a 'physiological adaptation' (more precisely, an acclimatory response) to increased altitudes. An animal's physiology can change within seconds (e.g., during sprint running), days or months (acclimatization), or during the course of development.

In the same hypothetical population, however, chronically high cardiac output is detrimental in the long-term because of hypertension and cardiac diseases, and individuals with this phenotype are selected against in the course of many generations. In an evolutionary perspective, high cardiac outputs would therefore be maladaptive (i.e., decreasing overall fitness), and selection would favor those individuals able to provide enough $\mathrm{O}_{2}$ to the tissues without higher workloads. If this phenotype has an underlying genetic component (and assuming that hypertense individuals had a lower probability of survival before they could pass their genes on), allelic combinations allowing for higher metabolic rates sustained by a lower cardiac output would increase in frequency in the population. These are true adaptations in the Darwinian sense, and we shall refer to those as 'genetic adaptations', which can be defined as "changes in the mean phenotype of a population due to changes in gene frequencies as a result of natural selection'. (Genetic drift and founder effects, also involved in phenotypic evolution through genotypic changes, are considered by evolutionary biologists as 'non-adaptive' processes; see below). 


\section{GENES AND DARWINIAN ADAPTATION}

Darwin's proposition of natural selection as the evolutionary process explaining biological adaptation relied on three major observations: species do not grow exponentially through time as predicted (Malthusian growth), animals from a single population are not all alike (e.g., many populations have considerable individual variation), and this variation is in part heritable. With competition and variation, organisms with traits that would increase their survival and reproductive success (i.e., fitness) would contribute differentially to the next generation. After several generations, that trait would be more frequent in the population and could eventually become the norm. Although the concept may seem trivial, 'the origin of species' was a huge collection of information emphasizing the complexity of evolutionary processes and patterns (even more when heredity mechanisms were a matter of speculation). Natural selection, however, was - and remains (e.g., Nespolo 2003) - the underlying common mechanism responsible for the origin of biological adaptations.

Today, the study of adaptation through natural selection relies on a slightly modified framework (see Nespolo 2003). First, phenotypic variation is the result of genetic (additive and non-additive) and environmental components, and how they interact (Fig. 1); the proportion of the phenotypic variance of a trait due to the (additive) genetic variation in the population is the 'heritability' of that trait (Falconer 1989, Roff 1997, Rupert \& Hochachka 2001). Second, the rate of evolution of a trait in response to selection will be proportional to the additive genetic variance of that trait ('fundamental theorem of natural selection', Fisher 1930), and the intensity of selection. With this framework, modern evolutionary geneticists have developed a robust body of knowledge on how several traits coevolve, the evolution of life histories and complex phenotypes (see Roff 1997, 2002 for reviews). In this context, several aspects may affect how animals will (or will not) adapt to their environment (i.e., high altitude) in a Darwinian sense.

\section{Evolutionary history}

Evolutionary responses to a given selective pressure will first depend on the nature of the organism/lineage under selection. Many traits may be present in a lineage not because it is adaptive to current conditions, but due to past events of selection, genetic bottlenecks, drift, etc. Nevertheless, evolutionary history has been practically ignored by many comparative physiologists (see Garland \& Adolph 1994). Recent advances in the 'comparative method' (see below), for instance, highlight how misleading studying Darwinian adaptation without considering the phylogenetic history of a lineage can be (e.g., Felsenstein 1985, Garland \& Ives 2000, Rezende \& Garland 2003).

Because of evolutionary history, many physiological responses may be deleterious or pathological when colonizing a different environment. For example, physiologists initially considered decreased of hemoglobin ( $\mathrm{Hb}$ ) for $\mathrm{O}_{2}$ affinities and increased red blood cells in humans as beneficial 'adaptations' to high altitudes, whereas now physiologists acknowledge that these responses may simply not be adaptive (Monge \& León-Velarde 1991). Furthermore, it is now acknowledged that high $\mathrm{Hb}-\mathrm{O}_{2}$ affinity is characteristic of hypoxia tolerant species, and such pattern has been observed across widely divergent vertebrate species (Hopkins \& Powell 2001).

The opposite may also be the case, and some traits already present in a lineage may facilitate the movement and survival of that lineage in a new niche or environment. These are considered 'exaptations' (Gould 1991); although they are adaptive (i.e., increasing overall fitness) to these new conditions, they evolved in that lineage before this new selective regime was encountered. For example, the high $\mathrm{Hb}-\mathrm{O}_{2}$ affinity observed in South American camelids (llamas and vicuñas) was initially thought to be an adaptation to high altitudes. Studies in Old World camels and dromedaries now show that high $\mathrm{Hb}-\mathrm{O}_{2}$ is a common trait in the entire family, being present in the lineage before the colonization of the Andes, suggesting that camelids in South America were 'preadapted' to colonize high altitudes (Monge \& León-Velarde 1991). (Many physiologists refer to exaptations as preadaptations, in spite of the misleading connotation of 'evolving structures in anticipation to future need'). 


\section{Population structure and genetic background}

Knowledge of the structure of a population and its genetic composition is now essential to understand phenotypic change on a microevolutionary scale (e.g., Grant \& Grant 1995). Natural selection will act upon the variation already present in the population, and evolution will occur when that variation is to some extent hereditary. Although optimality models have been applied quite successfully to study phenotypic evolution (e.g., Alexander 1982, Roff 2002), evolution ultimately depends on population structure and the genetic background of that population. Indeed, quantitative genetic models show that, although correlated traits could eventually evolve to their 'optimal', it may take several to many generations to attain that optimal in response to selection (Roff 1997).

Population structure can affect phenotypic evolution in several ways. First, it ultimately determines how many alleles may be 'immersed' in the population's gene pool, setting an upper limit to allelic variation. Second, as the effective population size decreases, genetic drift becomes increasingly important in determining evolutionary trajectories, and it may overcome the effects of natural selection. Third, immigration may provide enough gene flow to counteract the effects natural selection. This factor is particularly important in studies of altitude adaptation. Geographically isolated populations at high altitude may be under strong selection, and still not evolve or adapt because additional genes are flowing from low lands. In the hypothetical example above, for example, the scenario would be different if there was a high flow of individuals from the source population - many carrying genes potentially detrimental in the long-term - to high lands. According to Monge \& León-Velarde (1991), 'natural selection does not seem to have operated in humans as much as in other high-altitude animals, probably due to their migratory habits' (see also Brutsaert 2001).

Genes carry the information from one generation to another, and much physiological variation has a genetic component. For example, by crossing two inbred lines of laboratory mice, McCall \& Frierson (1997) found that the inheritance of running performance in hypoxia (hypoxic exercise tolerance) is consistent with expectations from a two-locus segregation model. At the population level, how information is passed on in each generation will ultimately determine the trajectories of phenotypic evolution. According to the fundamental theorem of natural selection, populations lacking additive genetic variance (e.g., high levels of inbreeding) will have a negligible response to selection. Genetic correlations may lead to co-adaptation of several traits in response to a single selective pressure, even when these traits do not provide any increased fitness (Lande \& Arnold 1983). As a case study, Rezende et al. (2004a) have shown that rodents from cold environments can attain higher maximum metabolic rates (MMR), and suggested that basal or resting metabolic rates (BMR) might be also higher in colder climates because both metabolic indexes were positively correlated. On the other hand, negative correlations (genetic trade-off) may constrain or delay the overall response to selection, and lead to adaptive valleys in the fitness landscape (i.e., certain combination of traits would have lower fitness).

\section{Identifying selective pressures}

High altitude environments impose two major constraints for endothermic organisms: cold temperatures, and hence higher thermoregulatory requirements, and low $\mathrm{O}_{2}$ availability. In addition, local factors may be influencing phenotypic evolution. For example, one would expect different intensities of selection (and evolutionary rates, if there is enough genetic variation) depending on the predatory regime populations encounter (e.g., Reznick \& Bryga 1987). To understand how these selective pressures are acting in a population is considerably more difficult, however, and many factors should be considered.

How organisms interact with their biotic and abiotic environment ('behavior' and/or 'ecology', in a broad sense) varies among individuals, populations and species, and will ultimately determine the nature and intensity of selection, as well as its spatial and temporal patterns. For example, although lower atmospheric pressures may constrain metabolic power output in any aerobic organism, reduced air density becomes an additional challenge for 
hummingbirds due to their hovering flight (Altshuler \& Dudley 2002). Mortality during winter would vary in intensity depending on whether individuals migrate to lower altitudes and warmer environments, hence selection could account for higher thermogenic capacities or hibernation in gregarious highaltitude populations, or increased ability to avoid cold temperatures in migrant populations. Behavior plays a crucial role in phenotypic evolution, therefore, and its importance in the evolution of physiological systems is now explicitly acknowledged (e.g., 'the centrality of organismal performance paradigm'; Garland \& Carter 1994, p. 593).

Selection may also be acting throughout ontogeny, and a single selective pressure may affect fitness functions of similar genotypes in many different ways. Many studies have reported high mortality rates in avian embryos relocated to high altitudes, for instance. Beattie \& Smith (1975) described an overall increase in egg hatchability from 16 to $56 \%$, after raising chickens from six generations in high altitude, highlighting how strong selection may be during ontogeny and how fast populations may respond in an evolutionary scale. In this context, physiology should evolve to decrease mortality during development and still lead to viable adult phenotypes, and novel developmental trajectories may be selected as a new environment is colonized (see Developmental plasticity section below).

\section{Physiology and life-history}

Understanding how selection shapes physiological traits and leads to adaptive systems ultimately depends on the linkages between an organism's physiology and its life history. Life history traits are those traits that contribute directly to the number of offspring an organism produces over the course of its lifetime. Commonly measured life history traits include the size and age when organism begins to reproduce, how often it reproduces, the number and size of offspring, and the relative allocation of time and energy to reproduction, versus growth and maintenance (Roff 2002, Stearns 1992). Life history traits thus make up the major components of Darwinian fitness and variation in life history traits amongst individuals in a population determine which genotypes will be represented in subsequent generations.

Physiology and life history are intimately related to each other because it is largely through physiological mechanisms that selection acts to produce adaptive strategies for allocating limited resources to the competing functions of growth, survival, and reproduction (Stearns 1992). Physiological adaptations for survival can thus place constraints on, or come at a cost to, the kinds of life history strategies that evolve. From this perspective, the evolution of physiological systems and life history strategies share the common feature that adaptations are embedded in a complex phenotype that incorporates trade-offs between integrated traits (see also Ghalambor et al. 2004). Comparisons of physiology and life history strategies between low and high altitude populations or species provide a particularly good framework for investigating these linkages because both physiological and life history traits often exhibit predictable patterns of variation across altitudinal gradients. Yet, few attempts have been made to critically examine the linkages between adaptive changes in physiological and life history traits.

Do physiological adaptations to breeding at high altitudes constrain the kinds of life history strategies that evolve? While such constraints can be predicted on theoretical grounds (Hayes et al. 1992), few empirical examples exist, although various lines of evidence from endothermic vertebrates suggest linkages between physiological and life history strategies. An examination of life history strategies of birds occupying low and high altitudes shows a repeated pattern of reduced fecundity and increased parental care at high altitudes (Badyaev 1997, Badyaev \& Ghalambor 2001). The increase in parental care at high altitudes is driven primarily by an increase in the amount of male contribution to the incubation, nestling, and post-fledging periods. Badyaev \& Ghalambor (2001) argue that this pattern arises because at high altitudes the colder temperatures, reduced food availability, and greater climatic unpredictability negatively impact juvenile survival, thus favoring a life history strategy of producing fewer offspring of higher quality as a buffer to these environmental conditions. Alternatively, or also contributing to this 
pattern, it could be that the increased energetic costs of breeding at high altitude (Weathers et al. 2002) reduces the amount of energy available for investment in offspring number. Evaluating such physiological constraints will require considerable more research on the physiological variability of birds along altitudinal gradients.

In contrast to birds, physiological adaptations to high altitude environments are much better known in mammals, whereas life history variation is less well understood. However, mammal life histories do appear to show a similar pattern of reduced fecundity at higher elevations as observed in birds (e.g., Bronson 1979, Zammuto \& Millar 1985). One of the few attempts to explore the conflicts between physiological and life history strategies is work summarized by WynneEdwards (1998) on the closely related dwarf hamster species in the genus Phodopus of central Asia. One species, $P$. campbelli occurs at higher elevations, experiences colder and more arid conditions and has a lower critical maximum temperature compared to a closely related species $P$. sungorus (Wynne-Edwards 1998). The less extreme habitat of $P$. sungorus allows females to rear litters alone, whereas in $P$. campbelli bi-parental care is necessary to alleviate thermoregulatory and water balance stresses on the female at higher elevations (Wynne-Edwards 1998). In this case, it appears that physiological adaptations for survival to a more extreme environment place constraints on the kind of reproductive strategies that can be favored by selection (Wynne-Edwards 1998). Thus, as is observed in birds, male Phodopus act to alleviate the challenges imposed by high altitudes on females attempting to rear offspring on their own. While it remains unknown whether similar physiological pathways shape avian life histories at high altitude, examination of the joint evolution of physiological and life history strategies offers a useful framework for examining the linkages and constraints between these complex systems.

In a more holistic perspective, physiology is always under selection: many physiological dysfunctions, at virtually any level of organization, may compromise homeostasis leading to decreased fitness or death (physiologists often take this for granted). The inherent complexity of physiological systems and their multifunctional nature is, therefore, a central component to be considered when studying adaptation. The cardiovascular system, for example, must deliver $\mathrm{O}_{2}$, hormones and energetic substrates to tissues, remove $\mathrm{CO}_{2}$ to lungs and metabolic wastes to kidneys, etc. Furthermore, regulatory systems must ensure adequate oxygenation of different tissues with variable metabolic workloads (e.g., rest or exercise), in a wide range of conditions, responding at different temporal scales (acute or chronic stimulus) - with many different constraints.

In this context, physics is the first factor constraining physiological function. A mouse cannot have the same absolute cardiac output of a whale simply because of size, and lungs will lose water during respiration through the same diffusive process by which $\mathrm{O}_{2}$ eventually reaches tissues. In a similar way, many physiological processes - such as membrane potential, or blood $\mathrm{pH}$ - will have narrow functional ranges, potentially constraining increased performance. Constraints also occur when a single physiological system is responsible for for the different functions (i.e. trade-offs). In very cold and hypoxic proper maintenance of environments, for example, 'mammals attempt to maintain both oxygenation and body temperature, although conflicts can arise because of the respiratory heat loss associated with the increase in ventilation' (Mortola \& Frappell 2000). Finally, given the non-linear behavior of many physiological functions, a response could be adaptive when it is moderate, and detrimental or pathological as it increases. For example, although a higher hematocrit may increase blood $\mathrm{O}_{2}$ carrying capacity, abnormally high values could be pathological (e.g., polycythemia) because of increased blood viscosity.

\section{Non-Mendelian parental effects}

Phenotypic variation will depend on genetic and environmental components, and how these factors interact. In this context, the phenotype of the offspring may be dependent not only on its own genotype, but also on the phenotypes of their parents (predominantly the mother). Maternal effects may or may not have a genetic 
component, having different sources: (i) the mitochondria or in cytoplasmatic factors inherited in the egg (e.g., more or less yolk to nurture the embryo), (ii) genetic differences underlying variation in parental care, and (iii) environmental conditions experienced by the mother may affect its contribution to the offspring's phenotype (Roff 1997, p. 241). In mammals, for example, the capacity of providing $\mathrm{O}_{2}$ to the embryos during gestation, and the female's lactation performance (e.g., phenotype of the mother) may affect drastically the offspring's body size (and related lifehistory traits), and probably has a genetic component. However, a starving pregnant female cannot nourish her offspring, and this source of variation is entirely environmental.

\section{PHENOTYPIC PLASTICITY: DEVELOPMENT AND} ADULTHOOD

Although most of the knowledge in ecological physiology has been built on studies comparing phenotypes of different individuals, populations, or species (see Comparative Method below), an additional level of variation must be considered: phenotypic changes within the lifetime of each individual (Fig. 1). Such changes are possible because the phenotype is a product of the interaction between genes and the environment. The set of phenotypic expression of a single genotype in response to naturally occurring (or experimentally imposed) environmental variation is called phenotypic plasticity. An environmental stimulus can change a phenotype both by (i) short-term modulation of the pre-existing physiological and biochemical systems (e.g. changing the concentration of modulators of the enzyme-substrate affinity, or altering the membrane fluidity through changes in its constituents), and/or by (ii) changing gene expression. Genetic adjustments usually take a longer time to be fully expressed and include (i) altering the concentration of the same enzyme isoforms or (ii) expressing different isoforms with different catalytic properties (Hochachka \& Somero 2002).

Several studies have described how environmental stimuli can alter developmental trajectories. This developmental plasticity may be crucial, since it tends to produce long-term and often permanent phenotypic changes (Spicer \& Gaston 1999, Wilson \& Franklin 2002, Spicer \& Burggren 2003). In humans, for example, several studies support an important developmental component explaining the bigger thoracic dimensions observed in populations at high altitudes, as well as in people growing up with untreated chronic respiratory diseases such as asthma (Monge \& León-Velarde 1991). Some authors claim that it is neither the genes themselves nor the discrete adult phenotypes that are main the target of natural selection, but the interaction between the genes and the environment through the ontogenetic trajectory that determine the capacity to deal with the environmental contingency (Schlichting \& Pigliucci 1993, 1995, McNamara \& Houston 1996).

The sensitivity of the phenotype to a particular environmental stimulus changes during development (Spicer \& Burggren 2003). If specific challenges are presented during 'sensitive periods' of the ontogeny, often called critical windows, the responses can be particularly influential on the adult phenotype. One example is the large and irreversible effects on adult respiratory patterns caused by a brief exposure to hypoxia during the first few weeks after birth in rats (Strohl \& Thomas 1997). Maternal effects (above) can be very important, because the environment the mother 'provides' (e.g., an appropriate nesting site in egg-laying species) will determine how the embryo develops. In humans, maternal residence at high altitude promotes a decrease in birth weight when compared to sea-level pregnancies, possibly due to a reduction of the uteroplacental and fetal volumetric blood flows (despite of the compensatory response of increased placental angiogenesis under such conditions). This constraint has been linked to a downregulation of fetal growth reflected in decreased materno-fetal circulating growth factors, placental nutrient transport, and fetal nutrition (Zamudio 2003).

During adulthood a short to mediumduration exposure to a different environment can also promote phenotypic changes. These events of phenotypic plasticity are usually referred as acclimatization when they occur in response to environmental changes in nature, and as acclimation when they are experimentally induced by environmental 

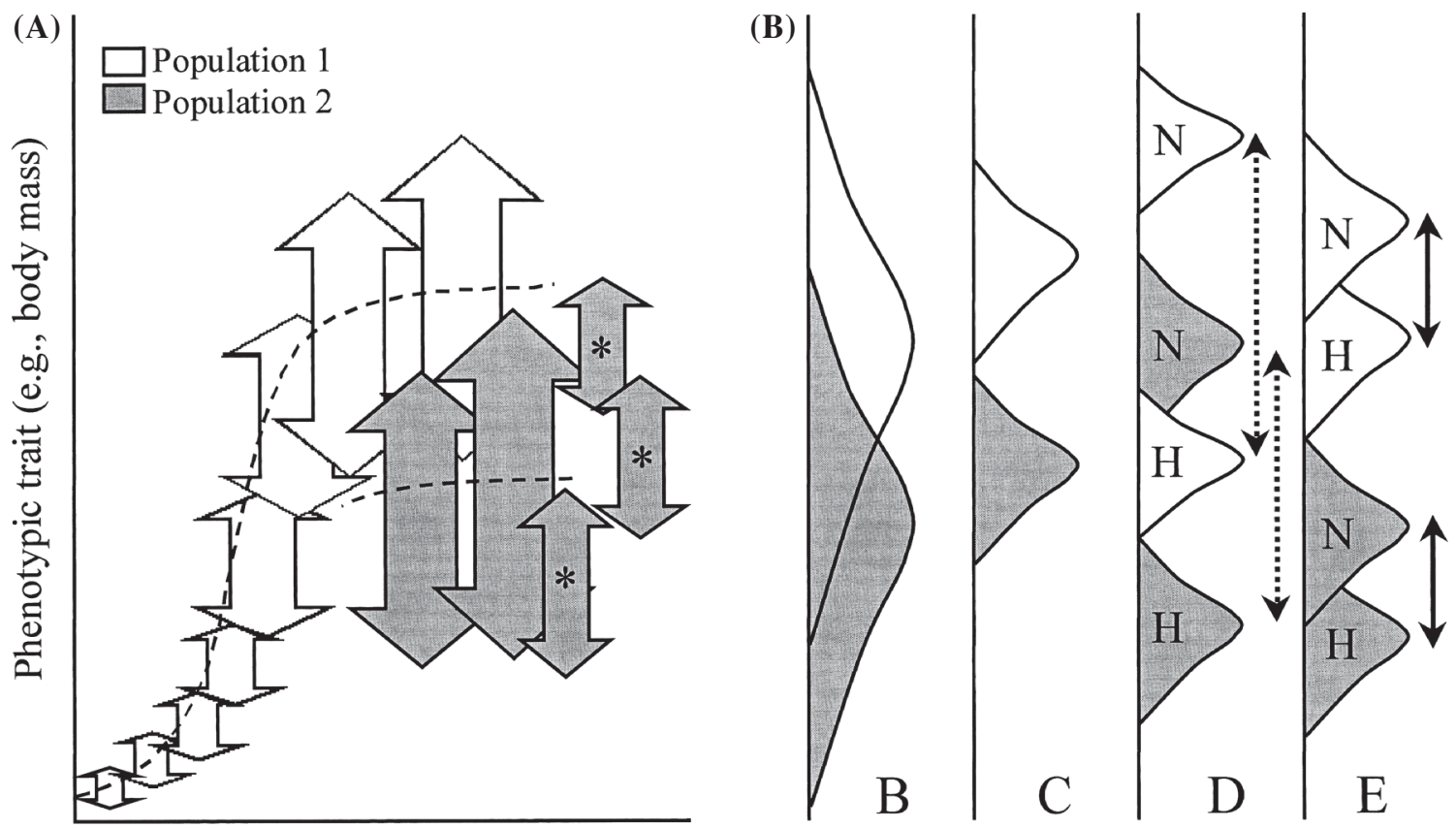

\section{Development 'Adulthood'}

Fig. 1: Schematic diagram showing the potential effects of plasticity - either through different developmental trajectories, or because of short-term acclimation or acclimatization - on phenotypic differences between species or populations (see also Garland \& Adolph 1994). (A) Two populations genetically different (i.e., population 2 is in average smaller than 1) develop in environments with different partial pressures of $\mathrm{O}_{2}\left(\mathrm{PO}_{2}\right)$. In both hypothetical populations, hypoxia leads to smaller body sizes, either by affecting growth rates during development (often irreversible effects, large arrows), or through modulations in food ingestion and activity levels during adulthood (reversible effects, small arrows with asterisks). (B) Expected distribution of size in each species when phenotypic measurements are performed completely 'at random' (e.g., different ages, sexes, developmental conditions, acclimated to either hypoxia or normoxia, etc). (C) Expected variation when both populations are studied under 'common garden' conditions (i.e., at similar $\mathrm{PO}_{2}$; all variance in this case is genetic or within-individual variation, because environmental variance is close to 0). (D) Hypothetical pattern if subsets of the populations developed at different controlled $\mathrm{PO}_{2}(\mathrm{~N}=$ normoxia, $\mathrm{H}=$ hypoxia). Note that specific developmental trajectories may constrain irreversibly the adult phenotype (dotted arrows), and groups developing in $\mathrm{N}$ and $\mathrm{H}$ within a population do not overlap despite of their genetic similitude (polyphenisms, Huey \& Berrigan 1996). (E) Hypothetical diagram of reversible plasticity (solid arrows), when both populations developed under controlled conditions and are submitted to different $\mathrm{PO}_{2}$ when adults (short-term acclimation or acclimatization experiments).

Diagrama representando como la plasticidad -durante el desarrollo o aclimatación y aclimatización- puede afectar comparaciones entre dos especies o poblaciones. (A) Dos poblaciones genéticamente distintas (i.e., la población 2 es en promedio mayor que la 1) se desarrollan en ambientes con distintos $\mathrm{PO}_{2}$. En las dos poblaciones hipotéticas, la hipoxia tiende a disminuir el tamaño corporal, ya sea cambiando las tasas de crecimiento durante el desarrollo (efectos comúnmente irreversibles, flechas grandes), o al afectar la ingesta o actividad durante la madurez (efectos reversibles, flechas chicas con asteriscos). (B) La distribución de tamaño corporal esperada si las comparaciones entre poblaciones o especies se hace sin controlar ninguna otra variable (e.g., se agrupan distintas edades, sexos, distintos $\mathrm{PO}_{2}$, etc). (C) Variación esperada si se compara las poblaciones en un ambiente controlado similar ("common garden"; toda la varianza fenotípica es genética o intraindividual, ya que la varianza ambiental es cercana a 0). (D) Patrón esperado si muestras dentro de cada población se desarrollan en $\mathrm{PO}_{2}$ contrastantes $(\mathrm{N}=$ normoxia, $\mathrm{H}=$ hipoxia). Nótese que las trayectorias de desarrollo específicas pueden generar diferencias fenotípicas irreversibles (líneas punteadas). (E) Diagrama hipotético mostrando la variación fenotípica cuando la plasticidad es reversible (líneas sólidas), como en experimentos de aclimatación o aclimatización en animales adultos. 
manipulation in the laboratory. Unlike developmental plasticity, such changes can be at least partially- reversible. For example, reversible seasonal acclimatization can allow an individual to tolerate temperatures in winter that would be lethal during summer and vice versa. As discussed above, many factors could account for non-adaptive plastic responses to environmental changes. Furthermore, it is important to remember that the ability of regulatory systems to respond to a particular environmental stimulus may have evolved in a context different from the one under study. For example, responses to tissue hypoxia and their underlying regulatory systems may have evolved to deal with exercise instead of high altitudes, and many of these responses might be deleterious when chronic.

Rates of acclimation can be highly variable, not only among individuals, but also between different traits in a single individual (e.g., Rezende et al. 2004b), and many of the factors underlying physiological responses must have a genetic component. Whether phenotypic plasticity can be considered a character itself, under genetic control at least partially independent of the mean phenotypic value, has been a major point of debate. Empirical support to the view of phenotypic plasticity as an independent character has come from studies demonstrating independent evolution of trait means and plasticities (e.g., Huey \& Berrigan 1996), as well as from experiments showing that phenotypic plasticity is responsive to selection (Schlichting \& Pigliucci 1998, for a review).

\section{APPROACHES TO STUDY HIGH ALTITUDE}

\section{ADAPTATIONS}

Multiple levels of organization - from genes to ecosystems - must be considered when studying Darwinian evolution and adaptation. Although 'proving' that a particular trait is an adaptation may be logistically difficult (i.e., by rejecting all other alternative hypotheses), physiologists now have tools to approach evolutionary problems more rigorously. The fundamental problem lies in demonstrating that (1) allelic changes underlying a particular trait were the result of selection, and (2) the correlation between that trait, performance and ultimately fitness. Only by combining different techniques, from organismal physiology to population genetics, can one study these two factors (Fig. 2). We summarize current methods employed to infer adaptive changes in response to selection, highlighting studies in deer mice (Peromyscus), given widespread geographic distribution of this genus, and the variety of techniques employed to study this rodent model's evolutionary history and altitude adaptation.

\section{Comparative method}

From Darwin's time to the present, comparing species or populations has remained the most general technique for addressing questions about long-term patterns of evolutionary change. In five species of Peromyscus reared under common garden conditions, BMR was significantly correlated with habitat primary productivity (Mueller \& Diamond 2001); and negatively correlated with temperature in 31 deer mice populations (although animals were not reared in common garden, MacMillen \& Garland 1989). These results suggest that BMR has evolved in response to different environmental productivity and temperature (which is correlated with altitude). After controlling for 'acclimatization effects' by comparing species in similar thermal environments, Hayes (1989) showed that populations of Peromyscus from high altitude have higher BMR than those from low altitude, suggesting that metabolism has evolved with altitude.

The comparative method has radically changed in recent years (e.g., Garland \& Adolph 1994) and with the development of analytical methods that incorporate phylogenetic information and use explicit models of character evolution to allow statistical inference (see Rezende \& Garland 2003, Garland et al. in press, for reviews). Importantly, many additional questions can now only be conceived in a phylogenetic context. Randomization methods developed to estimate 'phylogenetic signal' (the tendency of more related species to resemble each other, Blomberg et al. 2003), for instance, can provide insights on how geographical factors may have affected'historical patterns of speciation and vicariance. Among 57 species of rodents, altitude did not show significant signal (whereas latitude signal was highly significant) 
and was positively correlated with MMR (Rezende et al. 2004a); which suggests that (i) altitude was not a major geographical barrier to migration or colonization at that temporal scale (e.g., thousands to millions of years of divergence), and (ii) there is selection for increased MMR at higher altitudes, probably due to lower environmental temperatures.

\section{Selection experiments and quantitative genetics}

Quantitative genetics studies how quantitative traits are inherited in a population, and ultimately the role of the genetic background in phenotypic evolution (Roff 1997). Evolutionary physiologists are now studying, for instance, the underlying genetics of hypoxic tolerance in laboratory strains of Mus (see above), as well as aerobic performance and subordinate traits in laboratory and wild rodents (Dohm et al. 2001, Nespolo et al. 2003, Bacigalupe et al. 2004). These studies have reported very low heritabilities and additive genetic variance for BMR and MMR (during cold or exercise), and no genetic correlations between traits (although new results suggest a heritability of about 0.6 for MMR in a population of 'Phyllotis darwini, Nespolo personal communication). These studies require very large sample sizes and complex breeding designs. Another approach relies on measurements of individual consistency (repeatability) of a trait in a population (e.g., how consistent are the differences between individuals, Hayes \& Jenkins 1997). Repeatability is a prerequisite for natural selection to affect trait variation, and it may set the upper limit on the narrow sense heritability of the trait (Dohm 2002).

Selection experiments allow researchers to study evolution of complex phenotypes in action, under controlled conditions. Major advantages of selection experiments over comparative studies include: (i) evolutionary inferences do not rely only on a correlational approach, and (ii) environmental factors can be either controlled or included in the design (genotype by environment interaction). Because previous authors have already reviewed how selection experiments can be employed for studying physiological evolution and adaptation to hypoxic environments (e.g., Garland 2001, 2003), we will not address the topic in more detail here.

\section{Measuring selection in nature}

Studying natural selection in action in the field, and subsequent phenotypic evolution (e.g., Grant \& Grant 1995), is an ultimate goal of evolutionary physiology. Very few studies, however, have attempted to measure whether selection acts on individual variation in physiological traits and overall performance in natural populations (e.g., Jayne \& Bennett 1990). The basic protocol to study selection in performance is as follows. Some estimate of performance (e.g., running speed or endurance) is measured in a cohort of individuals of known age, which is then released in the field and the survivors are recaptured some time later. Several statistical procedures allow determining whether the probability of survivorship is correlated with a particular estimate of performance. Using this approach, Hayes \& O'Connor (1999) reported significant directional selection for higher MMR in a high altitude population of Peromyscus, during one particularly cold winter. (Note that recapture rates are not necessarily a good index of survivorship or fitness, if emigration occurs).

An alternative approach consists of comparing allelic or allozyme variation in different population (i.e., comparative study) to infer selection from patterns of geographic variation. In this case, candidate genes to be under selection are first identified, their contribution to phenotypic variation and ultimately fitness would then be addressed (Fig. 2). For instance, Peromyscus show an array of $\mathrm{Hb}$ polymorphisms, which are inherited basically as two different haplotypes (i.e., similar to what is expected with Mendelian inheritance of a single locus with two alleles), and haplotype frequencies are correlated with altitude (Snyder et al. 1988). Further research showed that individuals with the 'high-altitude haplotype' had increased $\mathrm{Hb}-\mathrm{O}_{2}$ affinities, and higher MMR during cold-exposure or forced exercised when measured at high altitudes, whereas the opposite was observed in the 'low-altitude haplotype' (Chappell \& Snyder 1984). Again, different lines of evidence support that the correlation between allelic frequencies and altitude may be due to local adaptation. 


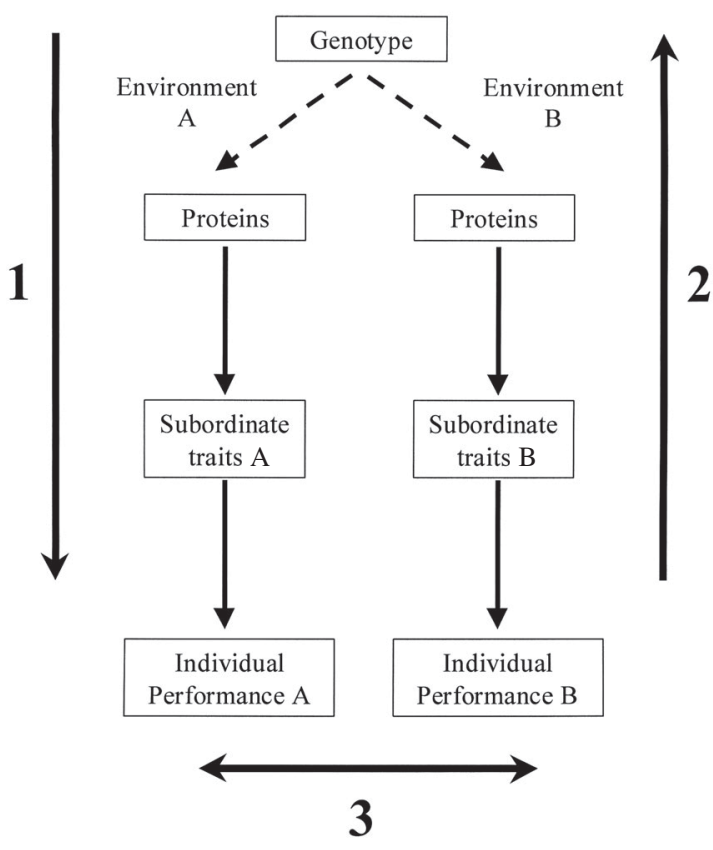

Fig. 2: Diagram showing three of the major approaches used to study evolutionary physiology. (1) The 'gene to phenotype' approach consists in screening for candidate genes affected by natural selection, and then studying the physiological and ecological mechanisms explaining the observed differences in allelic frequencies for that gene. (2) The 'phenotype to gene' approach initially identifies which phenotypes have evolved as true adaptations (e.g., comparative method, selection experiments), approaching the problem at lower levels of organization until the identification of the genetic architecture underlying these adaptations. (3) Factorial experiments, studying the interaction between genotypes (in this example, being the same) and the environment, can be used to study plasticity during both development and adulthood. (All approaches can be applied at different levels of organization, from whole individual performance to lower levels such as $\mathrm{Hb}-\mathrm{O}_{2}$ affinity, cardiac output, etc).

Esquema mostrando tres metodologías para estudiar la evolución de rasgos fisiológicos. (1) Del 'gen al fenotipo' se refiere a aquellos estudios donde primero se buscan genes potencialmente afectados por la selección natural, seguidos por estudios fisiológicos y ecológicos que explicarían mecanísticamente los cambios alélicos en esos genes. (2) Del 'fenotipo al gen' se refiere a estudios que primero intentan determinar los fenotipos que evolucionaron como adaptaciones Darwinianas, para después elucidar la estructura genética que conlleva a esos fenotipos. (3) Experimentos factoriales, que estudian la interacción entre el genotipo (que es constante en nuestro ejemplo) y el ambiente, pueden ocuparse para estudiar plasticidad fenotípica durante el desarrollo o madurez. (Cualquiera de esos métodos puede ser aplicado para estudiar rasgos fisiológicos a distintos niveles de organización).
Similarly, population geneticists can now determine candidate genes affected by selection, by comparing frequencies across several loci. As summarized by Storz \& Nachman (2003), the basic idea is that, 'if allelic variation at most loci is simply tracking stochastic demographic processes, loci under selection should produce a detectable signal against the genome-wide backdrop of neutral variation'. After a multilocus survey of allozyme variation in Peromyscus populations across a steep altitudinal gradient, Storz and colleagues have suggested that the albumin locus (or perhaps a closely linked gene) is a candidate for local adaptation. Nevertheless, albumin is associated with several physiological processes, and how variation at this locus translates in differences in physiology, performance and fitness, is not clear (Storz \& Dubach 2004).

\section{Developmental physiology and acclimation experiments}

Because the period of development is such a complex series of processes that results in a fully-functioning individual, it is important to understand how environmental perturbations can affect organisms during this period (Spicer \& Gaston 1999). Challenges occurring early in development may have quite different effects than those occurring at later life stages, since different organ systems have different 'critical windows' during which environmental perturbations will exert maximal effects (Dzialowski et al. 2002). Similarly, the amount of plasticity allowed for during ontogeny can define an individual's physiological capacities early during growth and development, which may have consequences for later survival (e.g., Tracy \& Walsberg 2001).

In this context, factorial designs are another useful tool to study the contributions of developmental and reversible plasticity in the adult phenotype. In this sense, many experimental designs may be employed to address different questions. Specific designs can provide insights about critical windows of development, whereas other approaches may allow partitioning of the phenotypic variance on a population in developmental and reversible components, and study their relative contributions to overall plasticity during adulthood. 
We emphasize that, although we have some knowledge of general effects of environmental variables in a phenotype, much remains to be done. For example, studies of reaction norms in physiological traits across many different environments, addressing physiological responses to combined stimulus (e.g., how would mice acclimate to different temperatures as $\mathrm{O}_{2}$ availability changes?), or determining the effects of the maternal environment in the offspring's phenotype, are scarce in the literature. The 'costs' of phenotypic plasticity, as well as the adaptive character of many physiological responses, must be tested rigorously (Huey \& Berrigan 1996).

\section{CONCLUSIONS}

The fields of physiology and evolutionary biology have long functioned as separate disciplines, with each providing their own important contributions to science, but without consistent attempts to examine their natural interrelationships. Comparative and environmental physiologists have been particularly successful describing (and demonstrating the functional importance of) patterns of physiological variation associated to life in challenging environments, such as high altitudes. However, a comprehensive understanding of how organisms adapt to different environments requires robust knowledge of the genetic, developmental and evolutionary mechanisms underlying these patterns of phenotypic variation. To achieve this goal, evolutionary physiologists need to embrace conceptual and methodological advances provided by evolutionary biology. Factors such as previous evolutionary history, population genetic structure, developmental plasticity, acclimatization, performance and fitness consequences of physiological variation, and the interactions of physiological systems with aspects of behavior and lifehistory traits need to be properly investigated in order to avoid the circular reasoning typical of the 'adaptationist program' (Gould \& Lewontin 1979). Similarly, evolutionary biologists will benefit from the quantitative mechanistic understanding of fitnessdetermining performance traits provided by physiological methods. High altitude offers a unique system to study the evolution of physiological traits and fortunately, several tools such as the phylogenetically corrected comparative analyses, quantitative genetic analyses, selection and factorial experiments among others, are now available to achieve this goal.

\section{ACKNOWLEDGEMENTS}

We are particularly grateful to the staff of the White Mountains Research Station at Barcroft for their constant support throughout the years; several studies cited here and performed by some of us would not be possible without their help. GAR also acknowledges a mini-grant from WMRS. ELR and CKG thank C del Agua for insights and support. This work was supported in part by NSF IBN-0111604 (KA Hammond and MAC). Finally, thanks to Mario Rosenmann for the great tutor he was, always sharing his knowledge and enthusiasm about science and life. Profe, muchas gracias por todo, y vamos a extrañarte.

\section{LITERATURE CITED}

ALEXANDER RM (1982) Optima for animals. Edward Arnold, London, United Kingdom. 112 pp.

ALTSHULER DL \& R DUDLEY (2002) The ecological and evolutionary interface of hummingbird flight physiology. Journal of Experimental Biology 205: 2325-2336.

BACIGALUPE LD, RF NESPOLO, DM BUSTAMANTE \& F BOZINOVIC (2004) The quantitative genetics of sustained energy budget in a wild mouse. Evolution 58: 421-429.

BADYAEV AV (1997) Avian life history variation along altitudinal gradients: an example with cardueline finches. Oecologia 111: 365-374.

BADYAEV AV \& CK GHALAMBOR (2001) Evolution of life histories along elevational gradients: tradeoff between parental care and fecundity. Ecology 82: $2948-2960$

BASSETT DR \& ET HOWLEY (2000) Limiting factors of maximum oxygen uptake and determinants of endurance performance. Medicine and Science in Sports and Exercise 32: 70-84.

BEATTIE J \& AH SMITH (1975) Metabolic adaptation of the chick embryo to chronic hypoxia. American Journal of Physiology 228: 1346-1350.

BLOMBERG SP, T GARLAND \& AR IVES (2003) Testing for phylogenetic signal in comparative data: behavioral traits are more labile. Evolution 57: 717 745.

BRONSON MT (1979) Altitudinal variation in the lifehistory of the golden-mantled ground-squirrel (Spermophilus lateralis). Ecology 60: 272-279.

BRUTSAERT TD (2001) Genetic and environmental 
adaptation in high altitude natives. In: Roach RC, PD Wagner \& PH Hackett (eds) Hypoxia: from genes to the bedside: 133-151. Kluwer Academic, New York, New York, USA.

CHAPPELL MA \& LRG SNYDER (1984) Biochemical and physiological correlates of deer mouse a-chain hemoglobin polymorphisms. Proceedings of the National Academy of Sciences USA 81: 5484-5488.

DZIALOWSKI EM, D VON PLETTENBERG, NA ELMONOUFY \& WW BURGGREN (2002) Chronic hypoxia alters the physiological and morphological trajectories of developing chicken embryos. Comparative Biochemistry and Physiology 131A: 713-724.

DOHM MR (2002) Repeatability estimates do not always set an upper limit to heritability. Functional Ecology 16: 273-280.

DOHM MR, JP HAYES \& T GARLAND (2001) The quantitative genetics of maximal and basal metabolic rates of oxygen consumption in mice. Genetics 159: 267-277.

FALCONER DS (1989) Introduction to quantitative genetics. Third edition. Longman, London, United Kingdom. 438 pp.

FEDER ME, AF BENNETT \& RB HUEY (2000) Evolutionary physiology. Annual Review of Ecology and Systematics 31:315-341.

FELSENSTEIN J (1985) Phylogenies and the comparative method. American Naturalist 125: 1-15.

FISHER RA (1930) The genetical theory of natural selection. A complete variorum edition. Oxford University Press, New York, New York, USA. 318 pp.

GARLAND T (2001) Phylogenetic comparison and artificial selection: two approaches in evolutionary physiology. In: Roach RC, PD Wagner \& PH Hackett (eds) Hypoxia: from genes to the bedside: 107-132. Kluwer Academic, New York, New York, USA.

GARLAND T (2003) Selection experiments: an underutilized tool in biomechanics and organismal biology. In: Bels VL, JP Gasc \& A Casinos (eds) Vertebrate biomechanics and evolution: 23-56. BIOS Scientific Publishers, Oxford, United Kingdom.

GARLAND T \& SC ADOLPH (1991) Physiological differentiation of vertebrate populations. Annual Review of Ecology and Systematics 22:193-228.

GARLAND T \& SC ADOLPH (1994) Why not to do twospecies comparative studies: limitations on inferring adaptation. Physiological Zoology 67:797828.

GARLAND T \& PA CARTER (1994) Evolutionary physiology. Annual Review of Physiology 56: 579621.

GARLAND T \& AR IVES (2000) Using the past to predict the present: confidence intervals for regression equations in phylogenetic comparative methods. American Naturalist 155: 346-364.

GARLAND T, AF BENNETT \& EL REZENDE (in press) Phylogenetic approaches in comparative physiology. Journal of Experimental Biology.

GHALAMBOR CK, DN REZNICK \& JA WALKER (2004) Constraints on adaptive evolution: the functional trade-off between reproduction and faststart swimming performance in the trinidadian guppy (Poecilia reticulata). American Naturalist 164: $38-50$

GOULD SJ (1991) Exaptation: a crucial tool for an evolutionary psychology. Journal of Social Issues 47: 43-65.
GOULD SJ \& RC LEWONTIN (1979) Spandrels of SanMarco and the Panglossian paradigm - a critique of the adaptationist program. Proceedings of the Royal Society of London B 205: 581-598.

GRANT PR \& BR GRANT (1995) Predicting microevolutionary responses to directional selection on heritable variation. Evolution 49: 241-251.

HAYES JP (1989) Altitudinal and seasonal effects on aerobic metabolism in deer mice. Journal of Comparative Physiology 159B: 453-459.

HAYES JP, T GARLAND \& MR DOHM (1992) Individual variation in metabolism and reproduction of Mus: are energetics and life-history linked? Functional Ecology 6: 5-14.

HAYES JP \& SH JENKINS (1997) Individual variation in mammals. Journal of Mammalogy 78: 274-293.

HAYES JP \& CS O'CONNOR (1999) Natural selection on thermogenic capacity of high-altitude deer mice. Evolution 53:1280-1287.

HOCHACHKA PW \& GN SOMERO (2002) Biochemical adaptation: mechanisms and process in physiological evolution. Oxford University Press, New York, New York, USA. 466 pp.

HOPKINS SR \& FL POWELL (2001) Common themes of adaptation to hypoxia: insights from comparative physiology. In: Roach RC, PD Wagner \& PH Hackett (eds) Hypoxia: from genes to the bedside: 153-167. Kluwer Academic, New York, New York, USA.

HUEY RB \& D BERRIGAN (1996) Testing evolutionary hypotheses of acclimation. In: Johnston IA \& AF Bennett (eds) Phenotypic and evolutionary adaptation to temperature: 205-237. Cambridge University Press, Cambridge, United Kingdom.

JAYNE BC \& AF BENNETT (1990) Selection on locomotor performance capacity in a natural population of garter snakes. Evolution 44: 12041209.

LANDE R \& SJ ARNOLD (1983) The measurement of selection on correlated characters. Evolution 37:1210-1226.

LYNCH GR, CB LYNCH, M DUBE \& C ALLEN (1976) Early cold exposure: effects on behavioral and physiological thermoregulation in the house mouse, Mus musculus. Physiological Zoology 49:191-199.

MACMILLEN RE \& T GARLAND (1989) Adaptive physiology. In: Kirkland GL \& JN Layne (eds) Advances in the study of Peromyscus (Rodentia): 143-168. Texas Tech University Press, Lubbock, Texas, USA.

McCALL RD \& D FRIERSON (1997) Inheritance of hypoxic exercise tolerance in mice. Behavioral Genetics 27: 181-190.

McNAMARA JM \& AI HOUSTON (1996) Statedependent life histories. Nature 380: 215-221.

MONGE C \& F LEÓN-VELARDE (1991) Physiological adaptation to high altitude: oxygen transport in mammals and birds. Physiological Reviews 71: $1135-1172$

MORTOLA JP \& PB FRAPPELL (2000) Ventilatory responses to changes in temperature in mammals and other vertebrates. Annual Review of Physiology 62: 847-874.

MUELLER P \& J DIAMOND (2001) Metabolic rate and environmental productivity: well-provisioned animals evolved to run and idle fast. Proceedings of the National Academy of Sciences USA 98: 1255012554 .

NESPOLO RF (2003) Evolution by natural selection: more evidence than ever before. Revista Chilena de Historia Natural 76: 699-716. 
NESPOLO RF, LD BACIGALUPE \& F BOZINOVIC (2003) Heritability of energetics in a wild mammal, the leaf-eared mouse (Phyllotis darwini). Evolution 57: 1679-1688.

REZENDE EL \& T GARLAND (2003) Comparaciones interespecíficas y métodos estadísticos filogenéticos. In: Bozinovic F (ed) Fisiología ecológica y evolutiva: teoría y casos de estudio en animales: 79-98. Ediciones Universidad Católica de Chile, Santiago, Chile.

REZENDE EL, F BOZINOVIC \& T GARLAND (2004a) Climatic adaptation and the evolution of maximum and basal rates of metabolism in rodents. Evolution 58: 1361-1374.

REZENDE EL, MA CHAPPELL \& KA HAMMOND (2004b) Cold-acclimation in Peromyscus: temporal effects and individual variation on maximum metabolism and ventilatory traits. Journal of Experimental Biology 207: 295-305.

REZNICK DN \& H BRYGA (1987) Life-history evolution in guppies (Poecilia reticulata) .1. Phenotypic and genetic changes in an introduction experiment. Evolution 41: 1370-1385.

RICHARDSON RS, CA HARMS, B GRASSI \& RT HEPPLE (1999) Skeletal muscle: master or slave of the cardiovascular system? Medicine and Science in Sports and Exercise 32: 89-93.

ROFF DA (1997) Evolutionary quantitative genetics. Chapman \& Hall, New York, New York, USA. 493 pp.

ROFF DA (2002) Life history evolution. Sinauer Associates Inc., Sunderland, Massachusetts, USA. $527 \mathrm{pp}$.

ROSENMANN M \& P MORRISON (1975) Metabolic level and limiting hypoxia in rodents. Comparative Biochemistry and Physiology 51A: 881-885.

RUPERT JL \& PW HOCHACHKA (2001) Genetic approaches to understanding human adaptation to altitude in the Andes. Journal of Experimental Biology 204: 3151-3160.

SCHLICHTING CD \& M PIGLIUCCI (1993) Control of phenotypic plasticity via regulatory genes. American Naturalist 142: 366-370.

SCHLICHTING CD \& M PIGLIUCCI (1995) Generegulation, quantitative genetics and the evolution of reaction norms. Evolutionary Ecology 9: 154168.

Associate Editor: Francisco Bozinovic

Received December 2, 2004; accepted March 1, 2005
SNYDER LRG, JP HAYES, \& MA CHAPPELL (1988) Alpha-chain hemoglobin polymorphisms are correlated with altitude in the deer mouse, Peromyscus maniculatus. Evolution 42: 689-697.

SPICER JI \& KJ GASTON (1999) Physiological diversity and its ecological implications. Blackwell Science, Oxford, United Kingdom. 241 pp.

SPICER JI \& WW BURGGREN (2003) Development of physiological regulatory systems: altering the timing of crucial events. Zoology 106: 91-99.

STEARNS SC (1992) The evolution of life histories. Oxford University Press, Oxford, United Kingdom. 249 pp.

STORZ JF \& MW NACHMAN (2003) Natural selection on protein polymorphism in the rodent genus Peromyscus: evidence from interlocus contrasts. Evolution 57: 2628-2635.

STORZ JF \& JM DUBACH (2004) Natural selection drives altitudinal divergence at the albumin locus in deer mice, Peromyscus maniculatus. Evolution 58: 1342-1352.

STROHL KP \& AJ THOMAS (1997) Neonatal conditioning for adult respiratory behavior. Respiratory Physiology 110: 269-275.

TRACY RL \& GE WALSBERG (2001) Developmental and acclimatory contributions to water loss in a desert rodent: investigating the time course of adaptive change. Journal of Comparative Physiology 171B: 669-679.

WEATHERS WW, CL DAVIDSON, CR OLSON, ML MORTON, N NUR \& TR FAMULA (2002) Altitudinal variation in parental energy expenditure by white-crowned sparrows. Journal of Experimental Biology 205: 2915-2924.

WILSON RS \& CE FRANKLIN (2002) Testing the beneficial acclimation hypothesis. Trends in Ecology and Evolution 17: 66-70.

WYNNE-EDWARDS KE (1998) Evolution of parental care in Phodopus: conflict between adaptations for survival and adaptations for rapid reproduction. American Zoologist 38: 238-250.

ZAMUDIO S (2003) The placenta at high altitude. High Altitude Medicine and Biology 4:171-191.

ZAMMUTO RM \& JS MILLAR (1985) Environmental predictability, variability, and Spermophilus columbianus life-history over an elevational gradient. Ecology 66: 1784-1794. 